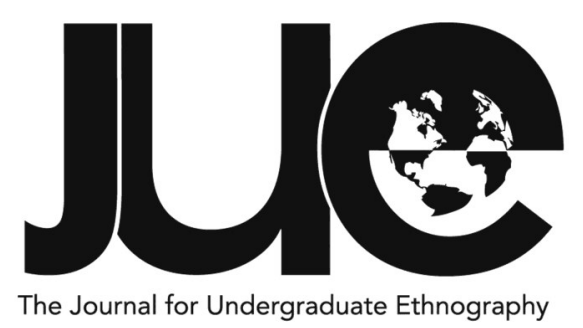

\title{
Growing Up Between Cultures: How Second-Generation Migrants Perceive and Construct "Home"
}

\author{
Francesca Celenta \& Catharina Klausegger \\ University College Maastricht \\ f.celenta@student.maatrichuniversity.com, c.klausegger@student.maastrichtuniversity.com
}

\section{ABSTRACT}

The word "home" can refer to a house, a family, a country, or even to a feeling of safety and comfort. Through increased mobility, the conception of home as a static place loses its meaning. For second-generation migrants, the children of migrants, the concept of home is ambiguous. They can have transnational ties to their parents' home country and the country they grew up in. The ambiguity leads second-generation migrants to construct home through reflective practices. Through in-depth interviews with eight second-generation migrants, we found that home is necessarily a complex and varied concept. The most important aspects to constructing a home are family (nuclear as well as extended family), a sense of community through shared values, and lastly reflective practices on what it means to grow up between cultures. While nuclear family provides the first safe space to create a feeling of home, feeling like part of a community is essential for feeling at home in a town or country. Some second-generation migrants find a community in the country they grew up in, while others feel rejected due to discrimination. In those cases, second-generation migrants search for cosmopolitan communities that share values of openness to difference.

Keywords: second-generation migrants; home; transnationalism; cosmopolitanism; mobility 
I say that I am Belgian because it's the quick answer but sometimes I want to say I'm from Africa, but I should explain that I'm from West Africa, and sometimes I want to say I'm from Senegal because some of my identity is from there. I never say I'm from Guinee Conakry except when people ask me what my origins are, and I say that, but it doesn't make sense for me. So yeah, Belgium is the quick answer but if I had to explain it to someone, I would say I feel Belgian and West-African.

W e asked Elise what she tells people when they ask her where she is from; a question that for a lot of people will have a straightforward answer becomes far more complicated for second-generation migrants. Rather than being a simple statement, the answer to "where are you from?" warrants a long explanation with multiple layers. The word "explain" speaks to the complexity and affective work that it takes for Elise to talk about where home is and the feelings she attributes to it. Through her words, she showcases her previous reflections on the topic. For many of the second-generation migrants who we talked to, conversations and previous reflections about what home is and what it takes to feel at home are common experiences. Having a "quick" answer to people's questions, while harbouring more complicated and mixed feelings about belonging somewhere and feeling at home, is something that links Elise's experience to that of other second-generation migrants.

Commonly, the word "home" often elicits a feeling of safety and comfort. Not only can it refer to a residential building or house, but also situations, a group of people, and even culture (Baffoe and Asimeng-Boahene 2012, 68). In the twentieth century, through the promotion of home ownership as a source of personal identity and social status, "home" as a house occupied by a nuclear family came to be a prevalent conception. This static concept is laden with the ideological understanding of a white, Western, middle-class family (Mallet $2004,74)$. As the world becomes increasingly mobile, "home" as a static concept loses its meaning. For second-generation migrants, the children of migrants, home can have multiple connotations referring to their country of residence, their parents' birth country, or both. For them, seen as both insiders and outsiders, home is an ambiguous space. Due to this position, second-generation migrants need to "actively construct 'home' from various vantage points and observe and practice both affinities and differences with the cultural others surrounding them" (Lloyd and Vasta 2017, 9). This position they occupy leads them to be very reflective of their experiences. Second-generation migrants' understanding of what it means to be a mobile person and how different geographical attachments and multiple cultural influences impact their identity can provide insight into the transformation of the meaning of home in an increasingly globalised, cosmopolitan world.

Through our research, we want to answer the question: How do second-generation migrants perceive and construct "home"? Second-generation migrants have a dual frame of reference due to growing up in one culture and being taught another by their parents. Thus, many second-generation migrants experience less attachment to or never "fully" experience either culture; therefore, they never "fully" feel at home in one particular place. Instead, second-generation migrants construct their homes through reflective practices and a sense of belonging to a community. First, we discuss previous academic work on the meanings attached to home, specifically in relation to the experiences of second-generation migrants. Second, we outline our methodology and ethical considerations in dealing with sensitive topics. Third, we situate our participants and elaborate on the three major themes found through indepth interviews with second-generation migrants: the role of family, sense of community, and growing up between cultures. Lastly, we conclude with how secondgeneration migrants construct home. 
The meanings of "home" in transnational times

Home has frequently been conceived as the physical living space that is occupied by a person, a family, or a group. In mundane communication, "home" refers to a house or a residential building (Baffoe and Asimeng-Boahene 2012, 68). Home can also refer to local neighbourhoods, cities, or countries (Ahmed 1999, 338) such as "birthplace" or "home town" (Baffoe and Asimeng-Boahene 2012, 68). Within that meaning, there can be different kinds of home: the place where one was born, where one grew up, where one lives at the moment, or where one spent a significant amount of time and has acquired a feeling of familiarity (Accarigi 2017, 192; Ahmed 1999, 340; Ralph and Staeheli 2011, 518-9). This feeling of familiarity refers to acquiring a sense of intimacy through the lived experiences of locality (Ahmed 1999, 341); in other words, being familiar with sensory experiences such as sounds, smells, and the landscape of a particular place (Hamilton 2017, 181).

The conceptualization of a static homelinked to only one particular location-is disturbed through mobility (Ralph and Staeheli 2011, 519). In modern times, through an increase in migration and globalization, the process of attachment to particular places has changed. The increase in mobility leads to temporality and uncertainty, which complicates the formation of affective attachment to places. While it might be harder to control for the uncertainty of migration, the focus on attachment to local places becomes more meaningful (Wiborg 2004, 417). Another significant change in the concept of home within the context of migration comes from the experience of "bifocality" or the "dual frame of reference" (Ralph and Staeheli 2011, 519). Migrants are influenced by both their country of origin and their destination; thus, they can refuse to be located in one singular place (Ralph and Staeheli 2011, 519). It is important to mention that sometimes the "refusal" to fit in, both in their country of origin and their destination, is less of a decision and more of a consequence arising from feelings and practices of exclusion. Nevertheless, second-generation migrants, if able to create transnational bonds, are likely to create particular attachments to different countries and can negotiate their conception of home.

An important factor that strongly influences the formation of attachment to the host country and/or their parents' birth country/ countries is the experience of racial and ethnic inequalities (Algan, Bisin, and Verdier 2012, 10). According to Akerlof and Kranton (cited in Algan, Bisin, and Verdier 2012, 10), dominant social groups define themselves by excluding other social groups. With regards to national identity, specific minority groups are used by the majority to define the boundaries of an authentic national identity. This represents an identity conflict for migrants as they have to decide whether to assimilate into the mainstream by giving up their minority social identity or hold onto their cultural attitudes and be excluded from becoming a national. This decision is also particularly important for the second-generation, as their parents have to decide which cultural traits to pass on and which majority traits their children should assimilate (Algan, Bisin, and Verdier 2012, 1314). Through the persistence of adopting certain cultural traits, first-generation migrants negotiate a trade-off between cultural traits of their minority social identity and the economic and social benefits of the mainstream social identity (Algan, Bisin, and Verdier 2012, 16).

While migrants can choose non-assimilation, it can also be forced due to cultural and/or economic exclusion. In response, they can adopt an oppositional identity (Algan, Bisin, and Verdier 2012, 10-11). These identities are defined in opposition to the majority and are associated with poor decision making and defiant/deviant behaviour. Due to the nature of these identities, theoretically, migrants can only assume either the oppositional or the mainstream identity. In reality, however, identities prove to be more complex and migrants can exhibit an oppositional identity and still form attachments to their host countries (Beaman 2017, 85).

The exclusion of minority groups based on ethnicity and race can be traced back to colonial times and the Enlightenment (Lentin 2008, 493). As Europe was rebuilt after the Shoah, the 
topics of race and ethnicity became taboo in many European countries, and public institutions strove to claim that Europe was "anti-racist." This suppression of discussion often led to a lack of designated vocabulary to talk about race and ethnicity. This ban has rendered any discussion of race and ethnicity nearly impossible due to a lack of designated language. However, European identity is still, just as it was before, defined by the Other, particularly the other ethnicity and the other religion (de Leeuw and van Wichelen 2008, 274). Due to exclusion from European identity, firstgeneration migrants can maintain and partly pass on the social identities of their countries of origin and develop new social identities that span across national boundaries. Smith (2014) theorizes that a "diasporic consciousness" is shared among African migrant communities throughout different European countries and the world (as cited in Beaman 2017, 85). The systematic exclusion they experience, the understanding that their identity is constructed around the concept of the Other, and the shared awareness of being different may lead second-generation migrants to refuse to be located in one place and create transnational ties and a non-static conception of home instead.

Migrants are considered to construct transnational identities as they "establish social fields that cross geographic, cultural, and political borders" and "develop and maintain multiple relations-familial, economic, social, organizational, religious, and political-that span borders" (Schiller, Basch, and Szanton Blanc 1992, 645). Hence, immigrants are considered transmigrants if they are able to sustain multiple links that cross borders. Transnationalism is a concept that has mostly been associated with first-generation migrants (Moore 2006, 159), as they are able to maintain their attachments to their home country through modern technologies of transportation and communication (Parutis 2011, 14). Secondgeneration migrants do not experience the same attachment to their parents' home country. While visiting extended family in their parents' home country and celebrating routinised events (like national holidays and birthdays), second-generation migrants create connections that can be described as sentimental or romantic, but they do not have the familiarity linked to daily routines, such as crossing paths with acquaintances in the street, knowing how to get to places by heart, or knowing when buses are likely to be late or early (Mallet 2004, 80). Moreover, secondgeneration migrants can experience exclusion based on their cultural identity due to being seen as foreigners by the local community (Bhimji 2008, 415).

Transnational ties and feelings of exclusion can lead to the development of cosmopolitan values (Roudometof 2005, 116). Compared to locals who identify with the culture and the country that they grew up in, cosmopolitans identify with multiple cultures and countries. Through the combination of transnational ties and feelings of exclusion, cosmopolitans can sometimes feel like they are never quite at home like locals. Instead, they create "this feeling at home in the world," which "could be specified as interest in or engagement with cultural diversity by straddling the global and the local spheres in terms of personal identity" (Gunesch 2004, 256). While cosmopolitans have local attachments, their cosmopolitan values, such as openness, take precedence over local attachments. Unlike locals that share experiences with the same culture, cosmopolitans find a sense of belonging to a community through the shared experience of creating a feeling of home that incorporates different cultural influences (Ebert $2017,21)$. This community can consist of other cosmopolitans or locals who are open to cosmopolitan values.

In light of recent studies on the meaning of home for migrants, the concept has shifted from being a fixed entity to being differential social constructions that can be negotiated and depend on reflexivity (Wiborg 2004, 417). Within this new conception, the home-making process is understood as the production and reproduction of domestic space and domesticity through affective labour, for instance, continuing cultural practices or adopting cultural practices from the destination country (Accarigi 2017, 201). Home-ness is created through the combination of people, objects, ideas, and enacted relationships within a local space (Hamilton 2017, 181). These 
factors create a sense of familiarity through the reiteration of everyday practices.

One prominent aspect of having this sense of familiarity and intimacy is that home is inherently linked with a feeling of safety and comfort (Ahmed 1999, 340; Wright 2009, 476). According to Keahey (1998, ix-x), home provides an oasis to relax and recuperate, and humans experience the feeling of "being at home" in multiple dimensions: social, psychological, intellectual, and spiritual. To feel "at home" and thus to feel safe is a universal human need (Keahey 1998, x). To that extent, home must fulfil the following conditions to create the feeling of safety: an environment where one can avoid scrutiny by others, a place of constancy where regular, everyday activities take place, and a space in which identities are formed (Baffoe and Asimeng-Boahene 2012, $69)$.

This paper attempts to expand on the literature presented by arguing that secondgeneration migrants do not have a fixed conception of being at home. Rather, the transnational ties they have created with multiple countries, the feelings of exclusion they may have experienced, and the cosmopolitan values they have adopted lead them to construct their feeling of home through reflexive practices and a sense of belonging to a community.

\section{Methodology}

Our research is a qualitative, exploratory study of how second-generation migrants perceive and construct the meanings of "home." The research follows the interpretivist paradigm, which states that objectivity only exists through the subjective meaning that people give to a situation; to find out the objective meaning of home, we sought to learn about the various meanings that second-generation migrants attribute to home and understand how they navigate the difficulties related to growing up between cultures.

We conducted semi-structured, in-depth interviews with eight second-generation migrants studying at Maastricht University. Using convenience sampling, four participants were recruited through a Facebook post and the others were acquaintances of the researchers and participants. The interviewees ranged from 18 to 22 years old (see table 1 ). All interviews were conducted in English and recorded and transcribed verbatim. The interviews lasted between forty-five and ninety minutes and took place at University College Maastricht. The questions we asked revolved around family, upbringing, external environment, feelings toward home, and what it means to be home.

We applied thematic analysis to the data. This method focuses on identifying patterns based on what participants say and, in some cases, how they say it (Braun and Clarke 2006, 79). We decided to code in an inductive way; rather than using pre-existing codes from the literature, we let the content of the interviews guide us. Some of our codes included struggling with the meaning of home, previous reflection on the topic, differences to parents, and celebration of holidays. After thorough refinement, we chose the following three themes to focus our analysis on: role of family,

Table 1. Research participants

\begin{tabular}{lllll}
\hline Name & Age & Gender & Parents' country/ies & Country of residence \\
\hline Eva & 20 & Female & Italy & Belgium \\
Elise & 19 & Female & $\begin{array}{l}\text { Colgium, Guinea } \\
\text { Conakry }\end{array}$ & Belgium, Senegal \\
Annie & 19 & Female & Iran & The Netherlands \\
Elena & 20 & Female & Vietnam & Germany \\
Valentin & 21 & Non-binary & Poland, Iran & Germany \\
Alex & 18 & Male & France, Cameroon & Germany \\
Ian & 22 & Male & India & Germany, India \\
Robert & 20 & Male & Poland, Malta & UK \\
\hline
\end{tabular}


sense of belonging and community, and growing up between cultures. The interviews contained a degree of reflexivity, and thematic analysis allows this aspect to come through (Braun and Clarke 2006, 82). By seeing our interviewees' experiences from their perspectives, we were able to make sense of their words in a more detached, critical way while still remaining true to their worldview.

\section{Ethical Considerations and Limitations of the Research}

Throughout the interviews, the majority of our participants expressed their struggle with what home means to them. The questions we asked were familiar to them as they had previously reflected on where they felt at home, what it took to feel at home, and what these things implied for the formation of their identity. The interviews revolved around the topics of family, growing up in their country of residence, and experiences with racism and discrimination. As some of these can be very sensitive topics, we asked participants to sign consent forms to make them aware of the type of questions that would be asked. To maintain privacy, we have changed our participants' names.

It is important to reflect on our position as researchers: neither of us is a secondgeneration migrant, and while we have tried to stay true to what our participants told us, it is possible that we did not always understand the depth and complexity of the experiences they shared with us. We are also white while the majority of our participants were people of colour, and it is important to consider that we are analysing and interpreting the experiences of minority groups from a privileged position. Additionally, it is also essential to mention a few of the limitations of our study. Our participants have different cultural backgrounds, have grown up in different countries, and/or their parents have immigrated from different countries. Although our varied sample could be a source for our diverse findings, we still found overarching trends across our interviewees' experiences.

\section{Home: "Feeling wanted and feeling that the place gives me what I need"}

In the process of analysing our interview data, we found that at an unconscious level, there is no difference between "being at home" and "feeling at home." We term this the unconscious inflation of house, household, and home so that these terms become synonymous. We understand the concept of "being at home" to be based on the modern, Western understanding of home as a house, owned and inhabited by one nuclear family undisturbed by mobility, racism, domestic abuse, or other factors inhibiting a sense of security. "Feeling at/of home," on the other hand, we understand as a product of affective labour that is located in a familiar space where relationships are enacted. This distinction will be a thread running throughout our analysis. Before diving into the discussion of the three themes, a short section situating our participants follows.

\section{Being university students in Maastricht}

Something our interviewees share is the social milieu they inhabit as Maastricht University students. Some of the questions we asked, such as Why did you decide to study in Maastricht? and Do you think Maastricht could ever feel like home to you? allowed us to gain insight into the social setting and everyday lives of participants. Maastricht is a small city situated in the south of the Netherlands, and students make up a large share of its population. While the university prides itself on having the most international community compared to other higher education institutions in the country, students mostly come from Western European countries. Thus, many of our interviewees did not feel represented inside the university nor in the wider city of Maastricht. While the majority of them also grew up in Western countries, their experiences still set them apart from other students who grew up being part of the majority group in their countries. Many interviewees mentioned the "Maastricht bubble" as a factor that limits their attachment toward the place they are studying in. Elise described the "Maastricht bubble" in the following way: 
Maastricht is quite a rich city. I don't see a lot of diversity... I don't see people asking for money in the street. In Belgium, when I go there, it's a big contrast, I see Black people, Arab people... so more diversity and I see the poverty and that's maybe a weird aspect, but for me home would be a place where I'm not in a bubble that hides these parts of society, like all the troubles.

The quotation shows that Elise is aware of living in a very wealthy environment where most students are privileged and voluntarily migrated to Maastricht in order to receive a good education. She mentions that for a place to feel like home, all parts of society need to be present while Maastricht seems to hide the "troubles" of the world. The lack of diversity in the city and the apparent absence of a wider socio-economic spectrum pose a challenge to being able to feel at home in Maastricht. Furthermore, Elise mentions that representation of Black people is also missing, pointing toward the fact that it is hard to feel at home in a place where no one looks like you. While other participants expressed similar views, some others also praised the fact that many students went to international schools and moved countries while growing up, and thus also have experiences of migration, albeit different ones from those of second-generation migrants. Alex mentioned that he found a community of like-minded people at university; for the first time, he is surrounded by people who understand him.

We could relate to everything because we both had some kind of lack of representation if I understood her experience correctly and also another one of my best friends, she's French-Malaysian... she lived in France, she understands it or the friend I told you about, the diplomat kid who also has never had a concept of home... so with all these people, I just love hearing from them and feeling confirmed in my experience.

Beaman $(2017,91)$ posits that as a consequence of the exclusion from mainstream society, second-generation migrants often create connections with each other. In Alex's case, we can see that he has bonded with people who share his cosmopolitan values and similar experiences. He finally feels at home at university because he is able to converse with people about his experiences of exclusion and marginalization, and his feelings are mirrored in what they also went through, creating an almost instant bond.

Something else that interviewees had in common is that they all were living in temporary housing. Annie mentioned that feeling a bit lost in her student house and still not knowing her way around Maastricht after a year of living in the city contributed to her discomfort and inability to feel at home. Similarly, when asked whether he could ever imagine Maastricht feeling like home, Robert said that what matters to him is that the place feels comfortable. He does not have a sense of being "at home" but rather experiences a "homely feeling" in different places. For example, he mentioned an Irish pub in Maastricht that reminds him of the times he used to hang out with his English friends, bringing a sense of familiarity to an unfamiliar city. Thus, in order to create a feeling of comfort in a new city, it is important to gain a sense of intimacy by experiencing locality and finding places or communities that make second-generation migrants "feel at home" (Ahmed 1999, 341; Hamilton 2017, 181).

\section{The role of family}

The role of family in constructing home can be divided into the role of nuclear family, that is, parents and siblings, and extended family, that is, grandparents, uncles and aunts, cousins. For our participants, nuclear family played a central role in "feeling at home." One of the conditions mentioned by Baffoe and Asimeng-Boahene $(2012,69)$ is that home should be a place where scrutiny is avoided, a place of safety and comfort. Elena, when asked about what makes her feel at home, described feeling secure and being taken care of and that her family provides these feelings.

For me personally, [family plays] a big role, because if I think of home, I also think of my family immediately because my parents are taking care of me usually when I go home. So, it plays a really big role I think... because I think also the feelings [of security and comfort, free from scrutiny] I just mentioned come from my family because they give me that feeling in the first place. 
Second-generation migrants often do not have extended family living in close proximity, which means that their immediate, familial support system is limited to their nuclear family. It is worth mentioning that all of our interviewees grew up in stable households and maintain good family relations with their nuclear family, and the comfort and security of nuclear family allowed our participants to "feel at home."

Our participants also expressed feeling comfortable and safe when visiting their extended family in their parents' home country. Eva explained that even though she did not feel like she was "coming home" when visiting her extended family, she did experience a "feeling of home." She was familiar with the values and traditions that her parents had taught her from their culture, and she recognised the familiar smell and taste of Italian food. Since being Italian is a big part of her identity, "feeling at home" equated to being surrounded by these familiar cultural elements in the place where her roots are. Other interviewees also explained that when visiting their extended family and recognizing their own values and traditions, they felt that they could explore and express a part of their identity that caused them to stand out in the country that they grew up in.

Our interviewees expressed that being able to explore and express the parts of their identity related to their parents' home country and culture resulted in feelings of relief. Being in an environment free of scrutiny regarding this part of their identity gave our interviewees a sense of ease. Elise described a sense of relief when being around African people in whom she could confide: "It's a relieving, safe feeling and a feeling that people can understand some troubles that I had.... I know part of the culture is from there, so I can talk about stuff and people understand and we can laugh about the same things." She repeated the word "understand" multiple times, which shows the importance of being surrounded by people who experience and live through similar situations. The ability to laugh about their troubles is indicative of a sense of comfort and security. Hence, Elise described feeling at home in Africa.

Alex, who did not feel at home in the country that he grew up in, mundanely referred to his mother's home country as "home" because, unlike in his hometown in Germany, he had not (yet) experienced hostility from the locals in France. "There is a very special connection with France. I have an emotional connection which leads me to being like, 'Oh my god, I wanna (sic.) go back home,' not meaning home in Germany, but home in France." In Alex's case, visiting his extended family has created a stronger "feeling of home" because the presence of scrutiny prevented the "feeling of home" in the country where he grew up. Second-generation migrants often refer to their parents' home country as an idyllic and magical place due to having created childhood memories (King, Christou, and Teerling 2009, 6).

However, Alex explained that although he has a strong emotional connection to France, he does not feel "fully" at home there: "I think it's just the attachment to the romanticization of it. I wouldn't like [living in France]; the attachment I have with France is purely emotional." Alex acknowledged that he has a romanticised idea of France due to the happy memories he associates with the country, such as visiting during the summer holidays. Yet, Alex stated that he would not like living in France because that would destroy the "purely emotional" bond he has with the country. When he had the choice to move there for university, he preferred not to, because living there would entail the possibility of encountering scrutiny and hostility from the locals. While the familiarity and comfort he feels in France allow him to create a "feeling of home" through his extended family, France is not "fully" home.

Although second-generation migrants can create a "feeling of home" in their parents' countries of origin through their extended family, there are some inhibitory factors. Geographical distance and differences in daily experiences with customs and popular culture make it harder to relate to extended family and to feel at home. Annie, who has a stronger attachment to the country that she grew up in, explained feeling different while visiting her parent's country in the following way:

Well, I don't feel like it's [Iran] my home because the people are different from me and they always see from a distance that I am not from there. I just act differently, I am quite loud there, because they have low 
voices, and I sometimes just yell, "Hey mum, look a bat." And I just dress a bit differently, I don't know, every country and cultures have their own styles (sic.), and I don't really fit in. ... I don't feel like it's my home, but I feel comfortable there and I have been there quite a lot so, I know the culture but still... I always compare it with my country, the Netherlands.

Annie, while describing a sense of familiarity and comfort when visiting Iran, mentioned that it is always apparent to her that she stands out from the local population. Rather than describing this in an exclusionary language, such as being seen as a foreigner, Annie related this to being "different" in how she acts, speaks, and dresses. Her visits to Iran prompted a reflective process on her identity, in particular on her Dutchness. Because she feels firmly rooted in her Dutch identity, she can reflect on the differences between the two countries and accept her status as a stranger in Iran.

Another inhibitory factor in constructing a "feeling of home" in their parents' home country is the language barrier between our interviewees and their extended family. Elise expressed that she and her extended family struggled with a language barrier as they had to communicate in English, which is none of their first languages. "We only came back for Christmas or during the summer and then we would see them, but there were these language barriers with my cousins.... But also, the fact that we saw each other twice a year. So, maybe it was kind of weird... at some point in the dinners (sic), it was kind of awkward." Elise mentioned both an issue of communication and the fact that she saw so little of her extended family that they were almost strangers. By describing the situation as "awkward" and "weird," she points toward feelings of discomfort and unease. Elise, however, added later on that she had become closer to her extended family in recent years due to living in closer proximity and better proficiency in English. Living near extended family allows second-generation migrants to become closer to their extended family as visits become more regular and familiarity can be created with the localities, the cultural practices and her family members.
Second-generation migrants can create a "feeling of home" in their parents' home country through extended family if they can overcome these obstacles, including geographical distance, language barriers, and cultural differences. However, secondgeneration migrants' attachment to their parents' home country is rarely as strong as first-generation migrants'. In contrast to their parents, second-generation migrants have a much smaller network of relationships in their parents' home country, as well as less familiarity with the locality. The exceptions to this were two of our interviewees, Elise and Ian, who had moved to their parents' home country for an extended period of time (two years and five years, respectively). Elise and lan had a much stronger connection to their parents' home country than other participants, which stems from having their own lived experiences in these countries rather than their parents' ability to pass on their attachment. Elise and Ian have made their own bonds with their parents' home country by creating routines and memories while living there.

Nuclear family and extended family provide important safe spaces for second-generation migrants to explore and express their identities and construct a "feeling of home." Nuclear family is particularly important as the immediate support system and a place free of scrutiny, while extended family helped second-generation migrants to explore their roots and parts of their identity that differentiate them from their peers in the country that they grew up in. When factors such as perceived cultural differences, lack of familiarity or contact with the extended family, and language barriers inhibit an attachment to their parents' home country, second-generation migrants look for a sense of community to construct a "feeling of home."

\section{Sense of belonging and community}

A sense of belonging is an important part of "feeling at home," and it is created when an individual is part of a community through having shared experiences with others. In the context of transnational mobility, "feeling at home" is not related to a geographical location but tied to the practice of routinised activities (Accarigi 2017, 192). Home can mean a locality 
where people have close relationships with their neighborhood or form attachments to a city square or a football team (Ahmed 1999, 340). Robert described the UK, the country where he grew up, as his "primary home" due to "having gone through the same education program" as his peers and having the same sense of humour. Annie, having grown up in a small Dutch town, described her experience of locality as being familiar with the streets and the people: "They always say that people from [a small Dutch town] are really proud of their city and I just miss the city itself sometimes, the cozy streets. When I walk around, I always see people I know, so that's nice. Now I have met a lot of people in Maastricht, so I sometimes see someone, but when I am at home, like always, like, oh hi, hi."

Annie places herself in the community of the town she grew up in, where she is a local and finds comfort in recognizing familiar faces when walking around. Having shared experiences allows second-generation migrants to "feel at home" in their country of residence because they feel that a large part of who they are is similar to the people around them. Robert and Annie can "be at home" in their country of residence because their sense of "feeling at home" has consistently been linked to their immediate environment, both the physical place and the community.

The "feeling of home" can, however, be disturbed when one is excluded from the immediate community. One reason for exclusion can be racism. Racism can accompany the migrant from childhood into adulthood, affecting different areas of social life: school, work, everyday life-it can happen on the street, on public transport, or in a supermarket (Greco 2011, 47). Alex, whose father is Cameroonian, recounted episodes of racism while growing up in a small German town.

When I'm here in Maastricht I forget that there are places that are not diverse, and I've actually spent all my life there. Every time I go back, I just feel the looks... there are these little things, you walk on the street and people just cross the street or you go into a shop and the alarm bell rings just because you have an alarm on your clothes and there you go-there is that look. Or your parents being disrespected because either they don't speak that good of a German (sic.) or people just believe they don't speak that good of a German (sic.) or just people constantly trying to undermine you. That's what the external environment did to my family or to me.

Alex perceived the external environment to be extremely hostile toward him as one of the few people of colour living in the town. The sentence "that's what the external environment did to my family" showcases the agency placed on the environment, as it acquires a life of its own and becomes emblematic of the oppression and the pain he felt. The racist episodes Alex recounted were many, spanning from more subtle things such as "looks" to direct, racially charged comments. The environment he grew up in led him to reject seeing Germany as his home. There was no inclusion in school and no sense of community that allowed him and his family to construct meaningful bonds. Not being accepted by the majority social group and being made to feel different can lead second-generation migrants to feel like strangers in their own country. They are "citizen outsiders"-citizens on paper, strangers in the public sphere (Beaman 2017, 4).

Experiences of racism can lead secondgeneration migrants to feel more at ease and more welcome in immigrant or cosmopolitan communities. For Alex, Maastricht was a new beginning; he found a cosmopolitan community as well as a community of second-generation migrants with whom he could talk about things that other people would not understand. "I've always been alone in this and finally I'm not and I just love not being the odd one out anymore, just being one of many. It's a great feeling, a lot of people don't like that feeling because they've done this all their lives, but I've never been one of many and I finally am one, so I enjoy it very much."

Alex talks about being part of a community in which he is "one of many" and no longer "the odd one out." Continuous exposure to racist attacks makes one's home unlivable; if home is supposed to be a place of comfort and security, always feeling on edge and having to defend oneself from offensive comments can lead to a 
complete rejection of the place where they grew up.

Alex expressed that the concept of "home" does not apply to him. In fact, for him, the word "home" refers mostly to a residential building or house. Alex also explained that he has attachments to several countries, but none of them truly feels like being at home. We asked Alex to describe "home" as a concept that would apply to him: "Feeling wanted and feeling that the place gives me what I need and also that I can provide something to that place. So that the place wants me and needs me. So, it's this symbiosis (sic.) kind of thing." Alex described home as a harmonious interaction between himself, the place, and the people. Home has to be a place that is welcoming and open to the expression of identity and a place over which one has agency - namely, the capacity and freedom to shape the physical environment and interpersonal relationships (Mallet 2004, 71). If the place has a "need" for him, Alex becomes essential in a way that counteracts his experiences of exclusion or isolation.

Experiences of exclusion can lead second-generation migrants to never "fully" feel at home. In turn, second-generation migrants search for migrant or cosmopolitan communities. The sense of belonging to these communities comes from shared experiences of having multiple cultural influences and transnational ties.

\section{Growing up between cultures}

The concept of transnationalism means having different links (political, cultural, religious) between two or more cultures that span across geographical borders. It is usually associated with first-generation migrants (Moore 2006, 159) because their roots are firmly planted in the country where they grew up and only later in their life did they move. The strong connection they have with their home country is linked to having a large network of family and friends and having spent a lot of time in one place, which allowed them to create familiarity and stability. This concept of having roots, both ethnically and culturally, in one place is different for second-generation migrants who have a harder time choosing to define only one place as home.
Alex, talking about his parents, says, "They grew up in their own country with their family all around them, they have that yo-yo thing. So, they just go back and then they're thrown out again into the world, but they always go back." Alex perceives that his parents, as first-generation migrants, have a different type of attachment to their home country. He senses that they belong to one place and will be inevitably attracted back. He does not experience this "yo-yo effect" because although he has a transnational identity, his bonds are not as strong- there is not a single "yo-yo" pulling him back.

My dad he always pushes... "You're a Cameroonian, you're not German" and every time he said that-that's something that did not resonate with me. It just didn't feel right what he said, and now I understand why because it's not right. Because I am Cameroonian but I'm not only Cameroonian, I'm also part German and part French and part human, like a citizen of the world.

The realization that he is not fully Cameroonian like his father wanted him to be shows that Alex is aware that he will never be "fully" something. There are different parts within him that have been shaped by the different cultures and influences that he grew up with. Unlike his parents that belong to their home country and are pulled back to their "home," he feels that this understanding of the concept does not apply to him: "I define my life in other terms, it's not home, it's not that, it's just people I'm around, it's just an environment." He feels that the parameters that other people use to talk about what home is to them do not apply to him. Instead, Alex is composed of different identities and cultural influences that do not allow him to fully fit into a single community; he found other parameters (like the people surrounding him) to establish a connection that could feel like home.

For second-generation migrants, the difficulty to define what "home" is results from the fact that their identity does not completely match the country where they were born and grew up. Elena, who grew up in Germany in a household where she was predominantly taught Vietnamese values, describes her experience as "growing up between cultures." 
She recounts never being fully immersed in the German traditions or the Vietnamese ones; both cultures were part of her upbringing and shaped different parts of her. The word "between" also points toward the fact that by trying to juggle both the German and Vietnamese way of living, she never fully experienced either one, setting her apart from the children who she grew up with.

Brocket $(2018,11)$ argues that the feeling of exclusion and in-betweenness experienced by second-generation migrants leads them to develop practices that centre around the self. Because they are not automatically from one culture, they are forced to reflect on their identity. Elena told us that the phrase "growing up between cultures" is what she likes to say to people who ask about the way she grew up or how she feels about being a second-generation migrant. The fact that she has prepared this sentence to tell people shows that she has spent time thinking about how growing up in Germany with immigrant parents has made her feel. It shows that she is conflicted about finding herself in this middle zone where she partially identifies with both Vietnam and Germany without experiencing the cultures wholly.

Eva, an Italian second-generation migrant who grew up in Brussels, expresses a sense of exclusion by mentioning that certain things about Belgian culture were completely foreign to her before she started university. "[There is] a lot of slang and language that I wasn't aware of. Sometimes you hear a word and I was like what does that mean? I wasn't aware of it. Also, artists, for example, Belgian music I didn't know, and they were singing a song that I didn't know because that wasn't part of what I was used to." Eva mentions not being in contact with Belgian pop culture because she was not used to it in her household. Therefore, "growing up between cultures" also means to feel left out because second-generation migrants might not be aware of certain aspects of the culture that other people feel very strongly about.

This reflection on the self and how they are different from the people around them leads second-generation migrants to be more critical of their homeland and host country. Second-generation migrants are influenced both by their parents' country of origin and by their countries of residence, thus they can have different perspectives on culture and refuse to be located in a singular place (Ralph and Staeheli 2011, 519).

Can I legitimately say that I am half Polish even though by blood or genetics I am Polish -Maltese? But do I really fit in with these communities-not really. Can I say that I am a real Pole?... And then the same with England, having those cultural influences. You can sort of take a step back and observe English culture because... you have a different perspective because of the other influences that you have on your life.

Robert shows the difficulties related to having a different perspective and how having ties to so many places and cultures can make it harder to find your own identity and a place in the world where you belong and feel at home. This "bifocality," or in Robert's case "multifocality," leads him to be more critical of the cultures he has connections to. This might lead to cherry-picking as second-generation migrants welcome certain aspects of one culture while rejecting others that they feel do not align with their values. The process of making oneself at home in these spaces involves negotiation and manipulation of identity to suit the context as a way of maintaining agency over the process of home-making (Lloyd and Vasta 2017, 6).

\section{Conclusion: Constructing home with transnational ties}

Our study found that nuclear family provides a crucial space for second-generation migrants to feel comfortable, safe, and taken care of. Nuclear family tends to be the main support system for second-generation migrants as the extended family often lives far away. While in some cases extended family can also provide a sense of comfort and a space where second-generation migrants can discover other parts of their identity, it also serves to show cultural differences. Being around extended family can make them aware of the ways in which their culture, their language and their everyday practices are different from their extended family members. A big part of fitting in with a community comes from having shared experiences with others. When second- 
generation migrants feel at home in the country that they grew up in, their experience of locality will be shared with their peers. If they face hostility from the locals in the form of racism, our interviewees were unable to recognize that place as their home. They might instead find a sense of belonging in other migrant communities where cosmopolitan values are upheld.

We make the important distinction between "feeling at home" and "being at home." Unconsciously, "being at home" still means residing in one physical location (house, apartment, residential building) with nuclear family. The household (family members) and the house itself are there to give the "feeling of home." This "feeling of home" refers to the familiarity with a locality-the lived experiences through everyday practices, lived relationships, and routinised activities that take place and provide a feeling of safety and comfort. Due to increased mobility, transnational ties, and cosmopolitan attitudes, a "feeling of home" becomes more detached from physical spaces. However, because "being at home" was understood as tied to a specific physical location that draws the person back throughout their life and is cultivated through a sustained "feeling of home" in that location, "being at home" becomes unattainable for some secondgeneration migrants. When interviewees discussed never being "fully" at home, they were referring to lacking the experience of "being at home." Instead, they create a "feeling of home" that is not tied to a specific location.

Being a second-generation migrant means having different influences in one's life that will inevitably shape one's identity and sense of home. These different perspectives make it hard to feel "fully" at home in a single geographical place. The many ties that second-generation migrants naturally have and develop throughout their lives lead them to be able to construct a "feeling of home" anywhere and everywhere, so long as they feel like they are part of a community. 


\section{Acknowledgements}

We would like to warmly thank our participants for the stories and experiences they shared with us, for the thoughtful ways in which they answered our questions, and for the time they dedicated to us. We would also like to thank our course coordinator, Ulrike Müller, and our tutor, Christopher Klän, for the skills they taught us, for encouraging us to always do better, and for the passion they transmitted to us. Finally, we would like to thank Martha Radice and the editors of the Journal for Undergraduate Ethnography for the opportunity to publish this undergraduate article. 


\section{References}

Accarigi, Ilaria Vanni. 2017. "Transcultural Objects, Transcultural Homes." In Reimagining Home in the 21st Century, edited by Justine Lloyd and Ellie Vasta, 192-206. Cheltenham, UK: Edward Elgar Publishing.

Ahmed, Sara. 1999. "Home and away: Narratives of migration and estrangement." International Journal of Cultural Studies 2 (3): 329 -347. https://doi.org/10.1177/136787799900200303.

Algan, Yann, Alberto Bisin, Alan Manning, and Thierry Verdier. 2012. "Introduction: Perspectives on Cultural Integration of Immigrants." In Cultural Integration in Europe, edited by Yann Algan, Alberto Bisin and Thierry Verdier, 1-48. Oxford, UK: Oxford University Press.

Baffoe, Michael, and Lewis Asimeng-Boahene. 2012. "The African Extended Family Network as an Inhibitor to the Reconstruction of 'Home' among West African Immigrants in the Diaspora." In Stranders in New Homelands: The Social Deconstruction and Reconstruction of "Home" among Immigrants in the Diaspora, edited by Michael Baffoe, 63-77. Newcastle upon Tyne:

Cambridge Scholars Pub.

Beaman, Jean. 2017. Citizen Outsider: Children of North African Immigrants in France. Oakland, California: University of California Press.

Bhimji, Fazila. 2008. "Cosmopolitan Belonging and Diaspora: SecondGeneration British Muslim Women Travelling to South Asia." Citizenship Studies 12 (4): 413-27. https:// doi.org/10.1080/13621020802184259.

Braun, Virginia, and Victoria Clarke. 2006. "Using Thematic Analysis in Psychology." Qualitative Research in Psychology 3 (2): 77-101. https://doi.org/10.1191/1478088706qp063oa.

Brocket, Tom. 2018. “From 'in-Betweenness' to 'positioned belongings': second-generation Palestinian-Americans negotiate the tensions of assimilation and transnationalism." Ethnic and Racia/Studies 43 (16): 135-54. https:// doi.org/10.1080/01419870.2018.1544651.

Ebert, Norbert. 2017. "Reflections on Home and Identity in Late Modernity." In Reimagining Home in the 21st Century, edited by Justine Lloyd and Ellie Vasta, 22-35. Cheltenham, UK: Edward Elgar Publishing. 
Gunesch, Konrad. 2004. "Education for Cosmopolitanism." Journal of Research in International Education 3 (3): 251-275. https:// doi.org/10.1177/1475240904047355.

Greco, Silvana. 2011. "Prejudice, Racism and Second Generation Migrants." In Multilingual Practical Training Guide, edited by Alenka Janko Spreizer and Silvana Greco, 44-51. Koper: Fakulteta za humanistične študije.

Hamilton, Olivia. 2017. "Senses of Home." In Reimagining Home in the 21st Century, edited by Justine Lloyd and Ellie Vasta, 179-191. Cheltenham, UK: Edward Elgar Publishing.

King, Russell, Anastasia Christou, and Janine Teerling. 2009. “Idyllic Times and Spaces? Memories of Childhood Visits to the Parental Homeland by Second-Generation Greeks Cypriots." Working Paper No. 56, Sussex Centre for Migration Research, University of Sussex. https://www.researchgate.net/ publication/237625083_Idyllic_Times_and_Spaces_Memories_of_C hildhood_Visits_to_the_Parental_Homeland_by_SecondGeneration_Greeks_and_Cypriots

Keahey, Deborah. 1998. Making it Home: Place in Canadian Prairie Literature. Winnipeg, Man.: University of Manitoba Press.

de Leeuw, Marc, and Sonja van Wichelen. 2008. "Transformation of 'Dutchness': From Happy Multiculturalism to the Crisis of Dutch Liberalism." In Identity, Belonging \& Migration, edited by Gerard Delanty, Ruth Wodak and Paul Jones, 261-276. Liverpool, UK: Liverpool University Press.

Lentin, Alana. 2008. "Europe and the Silence about Race." European Journal of Social Theory11 (4): 487-503.

Lloyd, Justine, and Ellie Vasta. 2017. "Reimagining Home in the 21st Century." In Reimagining Home in the 21st Century, edited by Justine Lloyd and Ellie Vasta, 1-18. Cheltenham, UK: Edward Elgar Publishing.

Mallett, Shelley. 2004. “Understanding Home: A Critical Review of the Literature". The Sociological Review 52 (1): 62-89. https:// doi.org/10.1111/j.1467-954X.2004.00442.x.

Moore, Deborah D. 2006. "At Home in America?: Revisiting the Second Generation." Journal of American Ethnic History 25 (2/3): 156-168. http://www.jstor.org/stable/27501693 
Parutis, Violetta. 2006. Construction of Home by Polish and Lithuanian Migrants in the UK. Economics Working Paper No. 64, Centre for the Study of Economic and Social Change in Europe, UCL School of Slavonic and East European Studies, London.

Ralph, David, and Lynn A. Staeheli. 2011. "Home and Migration: Mobilities, Belongings and Identities." Geography Compass 5 (7): 517-530. https://doi.org/10.1111/j.1749-8198.2011.00434.x.

Roudometof, Victor. 2005. "Transnationalism, Cosmopolitanism and Glocalization." Current Sociology53 (1): 113-135. https:// doi.org/10.1177/0011392105048291.

Schiller, Nina G., Linda G. Basch, and Cristina Szanton Blanc. 1992. Towards a Transnational Perspective on Migration: Race, Class, Ethnicity, and Nationalism Reconsidered. Annals of the New York Academy of Sciences, Vol. 645. New York, N.Y.: New York Academy of Sciences.

Wiborg, Agnete. 2004. "Place, Nature and Migration: Students' Attachment to their Rural Home Places." Sociologia Ruralis 44 (4): 416-432. https://doi.org/10.1111/j.1467-9523.2004.00284.x.

Wright, Susanna. 2009. "Going Home: Migration as Enactment and Symbol." The Journal of Analytical Psychology 54 (4): 475-492. https://doi.org/10.1111/j.1468-5922.2009.01798.x. 